\title{
"VEIO O RESULTADO DO EXAME": A COMUNICAÇÃO DE NOTÍCIAS DIAGNÓSTICAS (E COMO INVESTIGAÇÕES LINGUÍSTICO-INTERACIONAIS PODEM INFORMAR AS PRÁTICAS PROFISSIONAIS)
}

\author{
Ana Cristina Ostermann ${ }^{*}$ \\ Minéia Frezza ${ }^{* *}$ \\ Universidade do Vale do Rio dos Sinos \\ Escola da Indústria Criativa \\ São Leopoldo, RS, Brasil
}

\begin{abstract}
Resumo: Este artigo descreve, a partir da Análise da Conversa de base etnometodológica, a comunicação de noticias diagnósticas em 54 consultas de aconselhamento genético gravadas em áudio em um setor hospitalar materno-infantil do Sistema Único de Saúde (SUS) especializado em gestações de médio e alto risco. As interações foram transcritas em sua integra e as 18 interações em que há a comunicação de notícias diagnósticas foram analisadas quanto às ações interacionais que compõem essa tarefa. A análise de dados revela que a sequência de comunicação de notícias (SCN) assume características de uma espécie de sequência didática que colabora para a construção de entendimento de cada situação e para a coconstrução da própria notícia, tarefa que é compartilhada entre médico e paciente. Na comunicação de más notícias, em particular, observa-se um processo de agentivização do exame e de despessoalização da doença. O estudo descreve diferentes práticas linguístico-interacionais utilizadas para lidar com o sofrimento de pacientes e que podem subsidiar a formação de profissionais de saúde em áreas em que a comunicação de diagnósticos é uma constante.
\end{abstract}

Palavras-chave: Aconselhamento genético. Comunicação de notícias. Sequência didática. Agentividade.

1 INTRODUÇÃO

A comunicação de boas ou más notícias é um momento memorável. O fato é que, normalmente, conseguimos ter a nítida lembrança de onde estávamos, de quem nos contou, de como determinada notícia nos foi comunicada e, ainda, de nossa reação ao recebê-la. No que tange a más notícias, em particular, quem as comunica tem um papel fundamental, uma vez que não há como mudar os fatos a serem comunicados, mas há como amenizar o impacto do que é relatado por meio de como as notícias são entregues (MAYNARD, 2003).

\footnotetext{
* Doutora em Linguística. Professora Titular do Programa de Pós-graduação em Linguística Aplicada. Bolsista Produtividade do CNPq. E-mail: aco@unisinos.br.

** Doutoranda no Programa de Pós-Graduação em Linguística Aplicada e Mestra pelo mesmo Programa. E-mail: mineiafrezza@hotmail.com.
} 
Douglas Maynard (2003), analista da conversa que mais se dedicou ao estudo interacional de comunicação de notícias (em especial, de más notícias), sustenta que, apesar de existir muito a ser experenciado a partir do recebimento de alguma notícia, os instantes iniciais de seu recebimento são marcantes. A comunicação de notícias delimita o início de uma nova realidade, já que notícias - boas e ruins - representam rupturas de tamanha natureza na vida cotidiana que chegam a colocar em risco a noção, para quem as recebe, do que é ou não real (MAYNARD, 2003). Assim, as práticas interacionais por meio das quais se comunica ou se recebe notícias podem facilitar ou dificultar sua comunicação, recebimento e até mesmo entendimento (MAYNARD, 1996).

O período gestacional - período em que se encontram as participantes deste estudo - geralmente abarca experiências e sentimentos de entusiasmo e de expectativa de um desenvolvimento e parto tranquilos e saudáveis, resultando no nascimento de um bebê com saúde. Na maioria dos casos, as expectativas se tornam realidade. Contudo, quando isso não acontece (como, por exemplo, quando o bebê apresenta alguma malformação ou quando ocorre óbito), profissionais da saúde precisam ser capazes de comunicar as "más notícias" às famílias e de lidar com o cepticismo, sofrimento, recriminação, raiva e outras reações e emoções acarretadas pelas notícias (FALLOWFIELD; JENKINS, 2004).

No entanto, Maynard (2003) assevera que quando um diagnóstico é finalmente concluído e comunicado, mesmo quando culmine em uma notícia ruim, como alguma anomalia, marca-se o fim de uma espera angustiante e da condição de desconhecimento e de suspeita de que "havia algo de errado" na situação anterior. Ao receber as notícias sobre como a realidade anterior será modificada, finda-se a espera pelo que estava "por vir" e pode-se começar a planejar as mudanças necessárias para se lidar com a nova realidade.

Apesar de a comunicação de más notícias ser comum e de larga importância no contexto médico/a-paciente, essa prática ainda não foi investigada em pesquisas envolvendo dados reais de interação do cenário brasileiro. Da mesma forma, ainda não é (ou é apenas escassamente) tratada na formação médica no país. Conforme o Instituto Nacional de Câncer - INCA (2010, p. 17):

\footnotetext{
[...] a falta de preparo dos profissionais para a comunicação e o suporte emocional aos pacientes torna-se evidente, gerando silenciamentos, falsas promessas de cura ou comunicações abruptas de prognósticos adversos com sérios prejuízos à relação terapêutica e sofrimento de difícil assimilação, tanto para os pacientes como para os profissionais.
}

É dentro desse cenário - a saber, da lacuna de pesquisas no Brasil que se debrucem sobre interações naturalísticas envolvendo comunicação de notícias e que discutam o que e como uma investigação linguístico-interacional pode subsidiar a formação de profissionais que têm a comunicação de notícias (especialmente as más notícias) como uma tarefa constante - que este estudo emerge.

Este trabalho, que consiste em um subprojeto de um estudo maior intitulado "Uma mulher, um feto, e uma má notícia: a entrega de diagnósticos de síndromes e de malformações fetais - em busca de uma melhor compreensão do que está por vir e do que pode ser feito", vale-se da perspectiva teórico-metodológica da Análise da Conversa de 
base etnometodológica (AC), descreve a sequência interacional de comunicação de boas e más notícias em aconselhamentos genéticos que ocorrem no setor voltado às gestações de médio e alto risco em um hospital materno infantil do Sistema Único de Saúde (SUS). Os dados da pesquisa foram gerados a partir de interações naturalísticas, ou seja, interações que não emergiram por meio de entrevistas ou experimentos, mas que aconteceriam independentemente da realização de uma pesquisa (OSTERMANN, 2012). Tais interações consistem em 54 aconselhamentos genéticos gravados em áudio. Como nosso foco analítico é a comunicação de notícias diagnósticas, para a realização do estudo aqui relatado utilizamos apenas os 18 aconselhamentos genéticos que apresentam alguma notícia advinda de resultados de exames genéticos. Os aconselhamentos são conduzidos por um médico geneticista, cujo nome fictício é Jeferson, e participam deles a gestante ou puérpera, por vezes seu companheiro (que normalmente é também o pai do bebê da gestação corrente), algum/a outro/a acompanhante e, por vezes, a psicóloga do setor.

\section{COMUNICAÇÃO DE NOTÍCIAS E A ATRIBUIÇÃO DE VALÊNCIA}

Existe um senso comum compartilhado na organização social sobre o que se configura como boa ou má notícia. Como pontua Maynard (2003, p. 3-4), negamos e/ou tememos a morte, doenças, fracassos, perdas materiais, ao passo que apreciamos e celebramos a vida, gravidezes, nascimentos desejados, sucesso no trabalho, e temos a sensação de bem-estar quando nossos desejos se tornam realidade.

Em se tratando de diagnósticos, o oncologista Buckman (1984, p. 1597) define más notícias como:

[...] qualquer informação que possa alterar drasticamente a visão de um/a paciente sobre seu futuro [...]. Obviamente, o quão ruim uma notícia é vai depender, de certa forma, das expectativas dos/as pacientes naquele momento, do quão doentes se sentem e se já sabem ou suspeitam do seu diagnóstico ou estado de saúde atual.

Assim, não é possível categorizar uma notícia como boa ou ruim aprioristicamente. Até mesmo a morte pode não ser avaliada ou recebida como uma má notícia, dependendo da situação em que alguém se encontra. Dessa forma, a valência de uma mesma notícia pode ser atribuída de diferentes formas por diferentes interagentes. Maynard (1997) argumenta que só é possível verificar essa valência por meio das ações e respostas dos/as próprios/as interagentes e que acontecem na própria interação.

A valência que determinada notícia adquire deve-se a fatores como sua gravidade, quem comunica a notícia, quem é a pessoa principal envolvida, as suposições que cada um/a faz do que está acontecendo (MAYNARD, 1997). A pessoa para quem determinada notícia gera consequências é chamada por Maynard (1997) de "figura afetada" e, de acordo com o autor, a pessoa mais próxima da figura afetada parece ter uma posição privilegiada para atribuir valência à notícia.

\footnotetext{
${ }^{1}$ Consequential figure.
} 
Já o/a portador/a de alguma notícia, quando não é a figura afetada, pode orientar-se para a valência que ele/a próprio/a acredita que uma notícia tem, expondo seu aspecto positivo e encobrindo o ruim, o que pode ser observado interacionalmente por meio da sequencialidade das interações e do formato linguístico de cada turno (MAYNARD, 2003). Interagentes orientam-se para pré-anúncios ${ }^{2}$ que contêm hesitações, silêncios, interrupções, aspirações etc. como antecipadores de uma notícia ruim, ao passo que se orientam para falas diretas, aceleradas, em tom e volume altos etc. como indicadores de uma boa notícia (FREESE; MAYNARD, 1998; MAYNARD, 2003).

No contexto aqui estudado, que envolve aconselhamentos genéticos sobre a formação e saúde fetal, "[...] o recebimento da notícia de malformação em um filho, seja antes ou logo após o nascimento, é sempre uma vivência de crise intensa e equilíbrio emocional próximo à disrupção" (GOMES; PICCINI, 2010, p. 19). A crise vivenciada pelas figuras parentais de crianças com malformações inicia-se com a comunicação de uma má notícia, que causa uma ruptura do que fora idealizado e que pode repercutir em: "[...] choque, negação, tristeza e cólera [e demandar] equilíbrio e reorganização" (GOMES; PICCINI, 2010, p. 18).

\section{FORMATOS DE COMUNICAÇÃO DE MÁS NOTÍCIAS}

Maynard (1996) descreve três formatos de comunicação de más notícias:

1. Franqueza ou diretividade: as notícias são entregues diretamente.

2. Postergação: sugere que há más notícias, mas quem deve entregá-las evita fazêlo.

3. Antecipação: pistas vocais e não vocais que antecipam que uma má notícia está a caminho - e.g. expressões faciais de preocupação e seriedade. Algumas delas seriam:

i. Pré-anúncio: sonda o quanto o/a recebedor/a já sabe sobre o fato. Gera a relevância de uma ação seguinte (do/a recebedor/a do pré-anúncio) que sinalize que o/a portador/a pode prosseguir com o anúncio.

ii. Prefácio: variação do pré-anúncio que exclui a necessidade de um sinal para que o/a interlocutor/a prossiga.

iii. Pedido de desculpas: sinaliza que uma notícia ruim está por vir.

iv. Sequência lógica e silogismo incompleto: uma premissa geral é seguida de uma premissa particular, ou vice-versa, sem que seja apresentada, no entanto, a conclusão do silogismo, oportunizando que o/a próprio/a recebedor/a da notícia produza-a verbalmente.

\footnotetext{
${ }^{2}$ Pré-anúncio é um tipo de pré-sequência. Conforme Souza e Ostermann (2012, p. 165), pré-sequência consiste em um "momento na interação que precede uma sequência. Por exemplo, quando uma pessoa faz uma pergunta 'Posso lhe fazer uma pergunta?', o/a seu/sua interlocutor/a lhe diz 'Pode.', tem-se uma pré-sequência que anuncia que a sequência a seguir será um pedido de informação e o provimento da informação solicitada."
} 
Em um estudo com dados naturalísticos em contextos não institucionais, Schegloff (1988) observa que a fala pode se organizar de tal forma que a pessoa que deveria receber a má notícia acaba por apresentá-la. Por meio de pré-anúncios, prefácios e sequências lógicas de más notícias, quem recebe a notícia ruim pode tirar conclusões e verbalizar a notícia. Nesse mesmo sentido, o estudo conduzido por Maynard (1996, p. 119) conclui que a antecipação é o formato mais eficaz na compreensão em si da má notícia, enquanto a postergação, a diretividade e a franqueza exacerbam ainda mais "a interrupção da normalidade e aumentam a probabilidade de mal-entendidos", dificultando, assim, a compreensão.

\section{COMUNICAÇÃO DE NOTÍCIAS NO CONTEXTO MÉDICO/A-PACIENTE}

No contexto médico/a-paciente, comunicar notícias diagnósticas se traduz no dilema de como "[...] contar aos/às pacientes o diagnóstico e o prognóstico de forma honesta e em uma linguagem simples sem ser indelicado/a" (GIRGIS; SANSONFISHER, 1995, p. 2453). Em função desse dilema, alguns/as pesquisadores/as dos estudos interacionais (fora do Brasil) já têm se dedicado a olhar para interações naturalísticas de forma a buscar alternativas dentro das próprias práticas que já acontecem. Maynard (1992), por exemplo, descreve a organização por meio da qual as próprias figuras parentais chegam à conclusão de uma má notícia diagnóstica de deficiências no desenvolvimento de seu/sua filho/a (retardo mental, autismo etc.). $\mathrm{O}$ autor observa que isso acontece porque as figuras parentais são "guiadas" pelos/as profissionais por meio da sequência interacional "série de apresentação de perspectiva"” (MAYNARD, 1992, p. 333):

1. O/A médico/a pergunta a opinião ou o entendimento do/a interlocutor/a, ou convida-o/a a apresentar a sua perspectiva da situação.

2. O/A interlocutor/a responde sobre o seu entendimento ou provê uma avaliação da situação.

3. O/A médico/a anuncia e avalia a situação.

Essa sequência serve para obter a perspectiva das figuras parentais antes da comunicação de diagnóstico propriamente dito, minimizando, assim, o potencial de discordância, mal-entendido ou mesmo de dissonância em relação à realidade. Essa prática também proporciona certa agentividade aos/às recebedores/as de uma notícia, pois lhes permite lançar seus entendimentos e perspectivas sobre o caso em questão.

Quando há "alinhamento" entre médico/a e figuras parentais da criança com deficiência sobre a existência de um problema com ela, a comunicação do diagnóstico acontece sem percalços, enquanto na ausência de alinhamento, ocorre um trabalho interacional maior anterior até se chegar à comunicação do diagnóstico.

\footnotetext{
${ }^{3}$ Perspective-display series.

${ }^{4}$ Alinhamento é compreendido por Maynard (1992) como a concordância de pontos de vista e opiniões entre os/as interagentes.
} 
O protocolo SPIKES (BAILE et al., 2000), que foi elaborado por um grupo de oncologistas americanos/as e canadenses, foi desenvolvido como uma tentativa de suprir a dificuldade de comunicar más notícias a pacientes com câncer. Tal protocolo consiste em seis etapas que orientam oncologistas a:

a) planejar a entrevista;

b) avaliar a percepção do/a paciente ${ }^{5}$;

c) obter a solicitação do/a paciente para que detalhem o diagnóstico ${ }^{6}$;

d) oferecer conhecimento e informação ao/à paciente;

e) validar as emoções dos/as pacientes com respostas afetivas ${ }^{7}$;

f) resumir e traçar estratégias.

Baile et al. (2000) afirmam que os programas de graduação e de pós-graduação em geral são precários quanto à capacitação específica para a comunicação de más notícias, e a maior parte dos/as oncologistas aprende a fazê-la a partir da observação da prática de colegas mais experientes. Essa experiência também foi relatada pelo geneticista participante de nossa pesquisa. O protocolo SPIKES, apesar de não usar dados naturalísticos, já faz parte da formação de estudantes de medicina em algumas universidades. Contudo, ainda há muito a ser feito para suprir essa demanda.

No Brasil, os estudos que tratam da comunicação de boas e más notícias utilizam entrevistas post-factum com profissionais da saúde e/ou com pacientes (CUNHA; BLASCOVI-ASSIS; FIAMENGHI, 2010; GOMES; PICCININI, 2010). Ou seja, ainda não há pesquisas com dados interacionais naturalísticos sobre a atividade de comunicar notícias em contextos de saúde. Ainda assim, os estudos a partir de entrevistas em contextos que se aproximam daquele investigado aqui (pré-natal), reportam que o diagnóstico de malformação em bebês se revela como uma experiência bastante complexa e difícil, acarretando prejuízos psíquicos às figuras afetadas (CUNHA; BLASCOVIASSIS; FIAMENGHI, 2010; GOMES; PICCININI, 2010).

Cunha, Blascovi-Assis e Fiamenghi (2010), por exemplo, argumentam que grande parte da reação inicial à notícia da Síndrome de Down é determinada pelo tipo de informação recebida e pela maneira como ela é apresentada. Ao examinar a comunicação de informações sobre o diagnóstico a pacientes no Reino Unido, Heath (1992) aponta larga assimetria entre médico/a-paciente e pouca informação sobre o diagnóstico. Os dados de Heath (1992) mostram que os/as pacientes são extremamente passivos/as ao receber notícias diagnósticas, provendo apenas continuadores ou respostas mínimas de recebimento como "er" e "yeh"8 em tom descendente, a partir dos quais os/as médicos/as se orientam para o término da sequência de comunicação de diagnóstico e início das indicações de tratamento. Quando há algum marcador de recebimento de notícias que

\footnotetext{
${ }^{5}$ Essa etapa equivale à "série de apresentação de perspectiva" (MAYNARD, 1992).

${ }^{6}$ Baile et al. (2000) discutem a importância de se respeitar o quanto os/as pacientes realmente querem saber sobre suas doenças. Portanto, a ansiedade dos/as profissionais é aliviada quando os/as próprios/as pacientes solicitam por informações sobre seus diagnósticos.

${ }^{7}$ Algumas sugestões do protocolo SPIKES são: "Posso ver como isso lhe entristece."; "Percebo que você não esperava por isso.”; "Sei que esta não é uma boa notícia pra você.” (BAILE et al., 2000, p. 307).

${ }^{8}$ São continuadores em língua inglesa que equivalem a "ã" e "sim" em português.
} 
demonstra surpresa, como "oh, really, is $i t$ ", os/as profissionais reformulam suas avaliações e proveem mais informações. Heath (1992) também sustenta que o provimento adequado de informações diagnósticas é fortemente reconhecido pelos/as próprios/as profissionais como sendo crucial para que os/as pacientes adiram às recomendações de tratamento.

Diferentemente de Heath (1992), ao analisar consultas gravadas em serviços de atenção primária à saúde na Finlândia, Peräkylä (2006) conclui que, mesmo que o diagnóstico seja entregue no formato de uma simples declaração logo após o exame físico ou a leitura de um laudo laboratorial, os/as médicos/as participantes em seu estudo buscam oportunizar que os/as pacientes prossigam no curso do raciocínio diagnóstico.

Em sua análise sobre o formato da comunicação de notícias, Maynard $(1997,2003)$ observa uma sequência específica, cunhada pelo autor como "sequência de comunicação de notícias" (SCN), que envolve quatro turnos principais de fala: (1) anúncio, (2) resposta ao anúncio, (3) elaboração e (4) avaliação. Maynard e Frankel (2006), por sua vez, exploram como essa sequência se configura na interação médico/a-paciente no contexto de notícias diagnósticas, tanto em seu recebimento como em sua comunicação: boas notícias são recebidas com afiliação, ao passo que as ruins são recebidas com "desafiliação"10. Maynard e Frankel afirmam ainda ter encontrado "cuidado, circunspecção ou encobrimento em relação a más notícias diagnósticas, [...] e ousadia, assertividade, ou exposição com boas notícias diagnósticas" (2006, p. 270).

A partir de um estudo experimental - não envolvendo dados naturalísticos -, Del Vento et al. (2009) concluem que, ao comunicar más notícias, os/as médicos/as tendem a usar uma linguagem mais implícita (com eufemismos, modalizadores de mitigação, referentes generalizados e impessoais etc.), enquanto ao reportar boas notícias, tratamnas explicitamente, sem mitigação, com o uso de pronomes pessoais na primeira e segunda pessoa do singular etc. Del Vento et al. (2009) argumentam que o entendimento dos diagnósticos não é prejudicado pelo uso de linguagem implícita, já que vários/as pacientes (no caso de seu estudo, participantes atores) formulam o que entenderam após a comunicação de más notícias e discutem formas de tratamento.

\section{ACONSELHAMENTO GENÉTICO}

O termo genetic counseling foi cunhado pelo geneticista americano Sheldon C. Reed e traduzido no Brasil como aconselhamento genético (AG). Apesar do termo "aconselhamento", o médico geneticista brasileiro Pina-Neto (2008) explica que essas consultas não consistem em dar conselhos a famílias/pessoas com doenças genéticas sobre que decisões tomar, mas em informá-las, especialmente respeitando o princípio da neutralidade para que as decisões sejam tomadas com autonomia.

Na mesma perspectiva, o médico geneticista e professor brasileiro Décio Brunoni (2002, p. 101), baseado na American Society of Human Genetics, afirma que o AG envolve um/a profissional treinado/a para ajudar um indivíduo e/ou sua família a "[...]

\footnotetext{
9 “ah, sério, é".

10 Desafiliação é compreendida como a discordância dos/as interagentes sobre determinado tópico (MAYNARD; FRANKEL, 2006).
} 
compreender os fatos médicos, incluindo o diagnóstico, provável curso da doença e as condutas disponíveis." Em outras palavras, o trabalho do/a conselheiro/a genético é conversar com o/a paciente e com sua família para que entendam o que está acontecendo. É sobre essa questão que se debruça este artigo, i.e. a comunicação de notícias diagnósticas e a consequente elaboração do que elas significam.

\section{METODOLOGIA - COLETA E TRANSCRIÇÃO DOS DADOS E PARTICIPANTES}

A perspectiva teórico-metodológica da Análise da Conversa (AC) é utilizada neste artigo para a análise dos dados, que se dá, sobretudo, por meio da investigação da sequencialidade dos turnos de fala em busca de regularidades. Assim, não são analisados os pensamentos, as intenções e as vontades dos/as interagentes, salvo nas situações em que são demonstrados interacionalmente, já que daí são elementos passíveis de descrição.

Como a AC prevê o estudo de interações naturalísticas, i.e. interações que aconteceriam independentemente da realização de alguma pesquisa, gravamos 54 aconselhamentos genéticos realizados no hospital descrito anteriormente e separamos os 18 que apresentam alguma notícia advinda de resultados de exames. Por meio da AC, analisamos as ações realizadas na sequencialidade dos turnos de fala imediatamente anteriores e posteriores àqueles em que o geneticista comunica notícias e a ação de comunicar a notícia propriamente dita.

A gravação dos aconselhamentos genéticos -que aconteceu no período de outubro de 2013 a junho de 2014 - e a transcrição dessas interações foram realizadas por diferentes integrantes do grupo de pesquisa "Fala-em-interação em Contextos Institucionais e Não-Institucionais", coordenado pela Profa. Dra. Ana Cristina Ostermann. ${ }^{11}$ Os/As profissionais e pacientes que aceitaram participar da pesquisa, após serem informados/as sobre ela, assinaram o Termo de Consentimento Livre e Esclarecido (TCLE) que, por sua vez, já havia tramitado e sido aprovado nos Comitês de Ética (CEP) da universidade executora e do hospital onde os dados para a pesquisa foram gerados ${ }^{12}$.

A coleção de dados utilizada na pesquisa é composta por 18 AGs gravados e transcritos, conforme apresentada no Quadro 1 na página seguinte.

Importa dizer que esta categorização das notícias (no que se refere à sua valência) foi feita como base no posicionamento epistêmico ${ }^{13}$ que o geneticista apresenta ao avaliar o que determinada notícia (ou a falta dela) significa. Em outras palavras, a valência das notícias dispostas no Quadro 1 não foi decidida com base nas interpretações das autoras deste estudo, mas de forma êmica, i.e, a partir das avaliações realizadas pelo próprio geneticista ao interagir com as pacientes.

\footnotetext{
${ }^{11}$ A transcrição das interações foi feita através das convenções propostas por Jefferson (1984) e adaptadas pelo grupo "Fala-em-interação em Contextos Institucionais e Não-Institucionais", com base em sugestões do grupo GAT2 (SELTING et al., 2011), cuja versão atual encontra-se no Anexo.

12 Homologação do CEP da universidade executora: 078/2013 e do hospital onde os dados para esta pesquisa foram gerados: 344.748 .

${ }^{13}$ Posicionamento epistêmico é compreendido aqui como a expressão linguístico-interacional relativa ao domínio de determinado conhecimento (HERITAGE, 2012).
} 
Quadro 1 - Coleção de dados para estudo sobre comunicação de notícias

\begin{tabular}{|l|r|}
\hline \multicolumn{1}{|c|}{ Tipo de atendimento } & N \\
\hline Aconselhamento genético com comunicação de boas notícias & 1 \\
\hline Aconselhamento genético com comunicação de más notícias & 9 \\
\hline Aconselhamento genético com comunicação de boas notícias em contextos ruins & 8 \\
\hline N total & 18 \\
\hline
\end{tabular}

Fonte: Elaborado pelas autoras.

Como referido anteriormente, os dados deste estudo são oriundos de um hospital materno infantil do SUS. Para esse hospital são encaminhadas as mulheres com gestações de médio e alto risco - i.e. gestações gemelares ou com malformações, assim como gestantes diabéticas, hipertensas, com diagnóstico de toxoplasmose, entre outros -, onde há uma equipe especializada em medicina fetal composta por médicos/as obstetras, ginecologistas, ecografistas, uma ecocardiografista, uma nutricionista, profissionais de enfermagem, uma psicóloga e um médico geneticista.

O médico especialista em genética, Jeferson ${ }^{14}$, é quem normalmente trata com pacientes sobre questões relacionadas à indicação de exames mais especializados, como é o caso do exame de cariótipo fetal ${ }^{15}$. Jeferson também é o principal responsável pela comunicação de notícias diagnósticas acerca da saúde fetal em consultas que duram de quinze a oitenta minutos. As pacientes atendidas no local são frequentemente mulheres de baixa renda e escolaridade, têm entre 14 e 47 anos e nem sempre convivem com o pai do feto que estão gestando.

\section{ANÁLISE DE DADOS}

A análise de dados está centralizada em duas partes que apresentam duas ações fundamentais identificadas na organização da sequência de comunicação de notícias no contexto investigado: (a) pré-anúncio e (b) retomada dos resultados de exames anteriores e anúncio da notícia (propriamente dito).

\footnotetext{
${ }^{14}$ Todos os nomes dos/as participantes e/ou outras pessoas ou locais por eles/as referidos foram substituídos por nomes fictícios.

${ }^{15} \mathrm{O}$ cariótipo fetal é realizado por meio da análise do líquido amniótico ou do sangue fetal coletados através de um procedimento de punção, chamado de amniocentese - no caso do líquido amniótico - e de cordocentese - do sangue do cordão umbilical. O cariótipo fetal possibilita o diagnóstico de doenças cromossômicas (como síndromes, a doença de Tay-Sachs ou galactosemia, entre outras).
} 
O anúncio da chegada de laudos de exames que podem diagnosticar anomalias fetais (tratados aqui como "resultados") se configura como um pré-anúncio de que há notícias a serem entregues naquela consulta. Ao analisar a sequência das ações envolvidas na comunicação de boas notícias, percebe-se que os desenhos de turnos de fala colocam o médico e a equipe de medicina fetal como agentes da comunicação da notícia, ao passo que na comunicação de más notícias os desenhos de turnos trazem os exames e seus resultados como os agentes da comunicação. Os excertos a seguir mostram situações de comunicação de boas notícias.
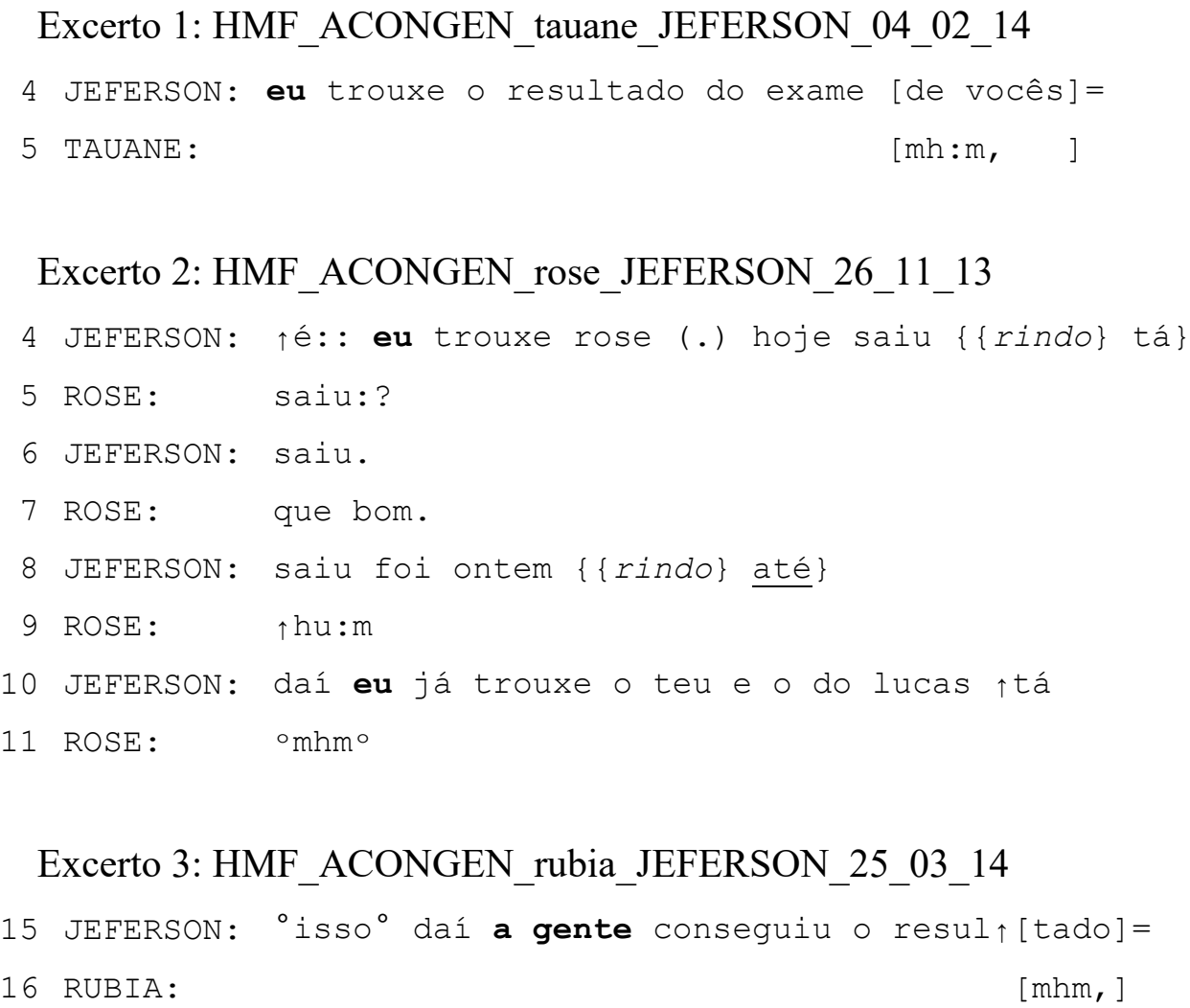

O uso de "eu" e "a gente" como agentes a ação de trazer a notícia nos turnos que realizam os pré-anúncios de notícias diagnósticas alocam o profissional e a equipe de medicina fetal na posição de porta-vozes de boas notícias. A prática de colocar a primeira pessoa como agente portador da notícia foi denominada na literatura como "pessoalização" da comunicação de boas notícias (DEL VENTO et al., 2009), enquanto que a prática de usar "a gente", evocando a institutição para si e o/a falante como um/a representante dela, como "institucionalização" (da comunicação de boas notícias) (DREW; HERITAGE, 1992; SACKS, 1992 ${ }^{16}$ ).

\footnotetext{
${ }^{16}$ Cabe aqui observar que Drew e Heritage (1992) e Sacks (1992) observaram a institucionalização através da forma pronominal da língua inglesa "we" ("nós" em língua portuguesa), que se refere à primeira pessoa do plural. Em língua inglesa, não há expressões nominais pronominalizadas para a primeira pessoa do
} 
Nas interações aqui investigadas, após o pré-anúncio das boas notícias, as gestantes tendem a oferecer algum continuador (como um "mhm"), que devolve o turno ao profissional para que ele dê continuidade à sequência. $\mathrm{O}$ que mostramos na próxima subseção, contudo, é que, recorrentemente, o profissional atrasa o anúncio da notícia em si para primeiramente fazer uma retomada da indicação do exame e de sua importância.

Já nos casos de comunicação de más notícias diagnósticas, é recorrente a despessoalização do agente portador da notícia diagnóstica. O excerto apresentado a seguir indica como o exame passa a ser quem, realmente, pré-anuncia um diagnóstico indesejado.

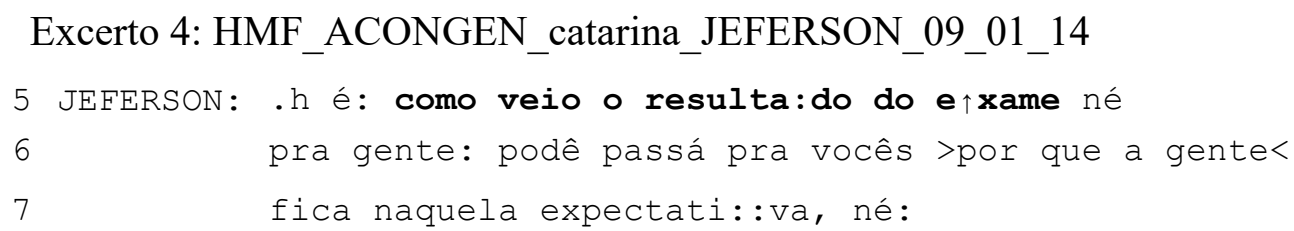

O diagnóstico na interação da qual advém o Excerto 4 é de Síndrome de Down (a continuação dessa interação é apresentada nos Excertos 6 e 7). Observe-se que, nesse caso, o pré-anúncio não apresenta um agente humano que "traz" o resultado dos exames (ao contrário do que fora observado nos Excertos 1 a 3). No Excerto 4, que se caracteriza como o pré-anúncio da comunicação de uma notícia ruim, observa-se que é o "resultado do exame" (de cariótipo fetal) que ocupa a posição de agente do verbo "vir", i.e. o resultado veio (1. 5).

Ainda nos Excertos 1-3, que se apresentam como pré-anúncios de boas notícias, o profissional e a equipe médica ocupam posição de sujeitos da ação de "trazer" os resultados dos exames - i.e. o médico e a equipe são os portadores das boas notícias. Por outro lado, no Excerto 4, o resultado do exame é apresentado como o portador das más notícias ao assumir características de "animação" como agente do verbo "vir". A característica de "animação" dos exames também é observada em outros momentos do AG, decritos na próxima subseção.

\subsection{RETOMADAS E ANÚNCIOS}

Como mencionado anteriormente, o anúncio de uma notícia diagnóstica é frequentemente atrasado pela ação de retomar a necessidade de exames e de medidas que sustentam o diagnóstico. Essas retomadas acontecem mesmo em situações de comunicação de boas notícias, apesar de que nesses casos elas tendem a ser mais curtas do que quando antedecem o anúncio de más notícias. Contudo, há diferenças.

As retomadas que compõem a sequência de comunicação de boas notícias ocorrem em dois possíveis momentos: antes ou depois do anúncio da notícia, enquanto que as

plural, como é o caso de "a gente" em língua portuguesa. Ou seja, tomamos aqui o uso de "a gente" como primeira pessoa do plural (ainda que conjugado em terceira pessoa do singular) e, por isso, equivalente ao uso de "nós", em língua portuguesa, e ao "we", em língua inglesa. 
retomadas em sequências de comunicação de más notícias sempre acontecem antes do anúncio da notícia em si. Assim, retomadas após o anúncio de boas notícias iniciam com a própria explicação do resultado do exame. Já as retomadas que antecedem o anúncio das notícias são compostas pela menção dos sinais e sintomas evidenciados nos exames anteriores e que levaram à própria indicação do exame cujo resultado está sendo comunicado naquele momento. Para ilustrar essa observação, apresentamos uma retomada que antecede e outra que sucede o anúncio de boas notícias de uma interação. Em seguida, apresentamos uma retomada que antecede uma comunicação de más notícias.

O Excerto 5 advém de uma interação que ocorre entre o geneticista (Jeferson), a gestante Tauane e seu marido. Todos os exames de avaliação da saúde fetal haviam tido resultados normais até então. Contudo, havia sido indicada ao casal a investigação de seus cariótipos, em função de seu histórico de perdas gestacionais, o que poderia estar associado a alguma malformação genética. Nessa interação acontece a comunicação do resultado dos cariótipos do casal e a explicação de seu significado.

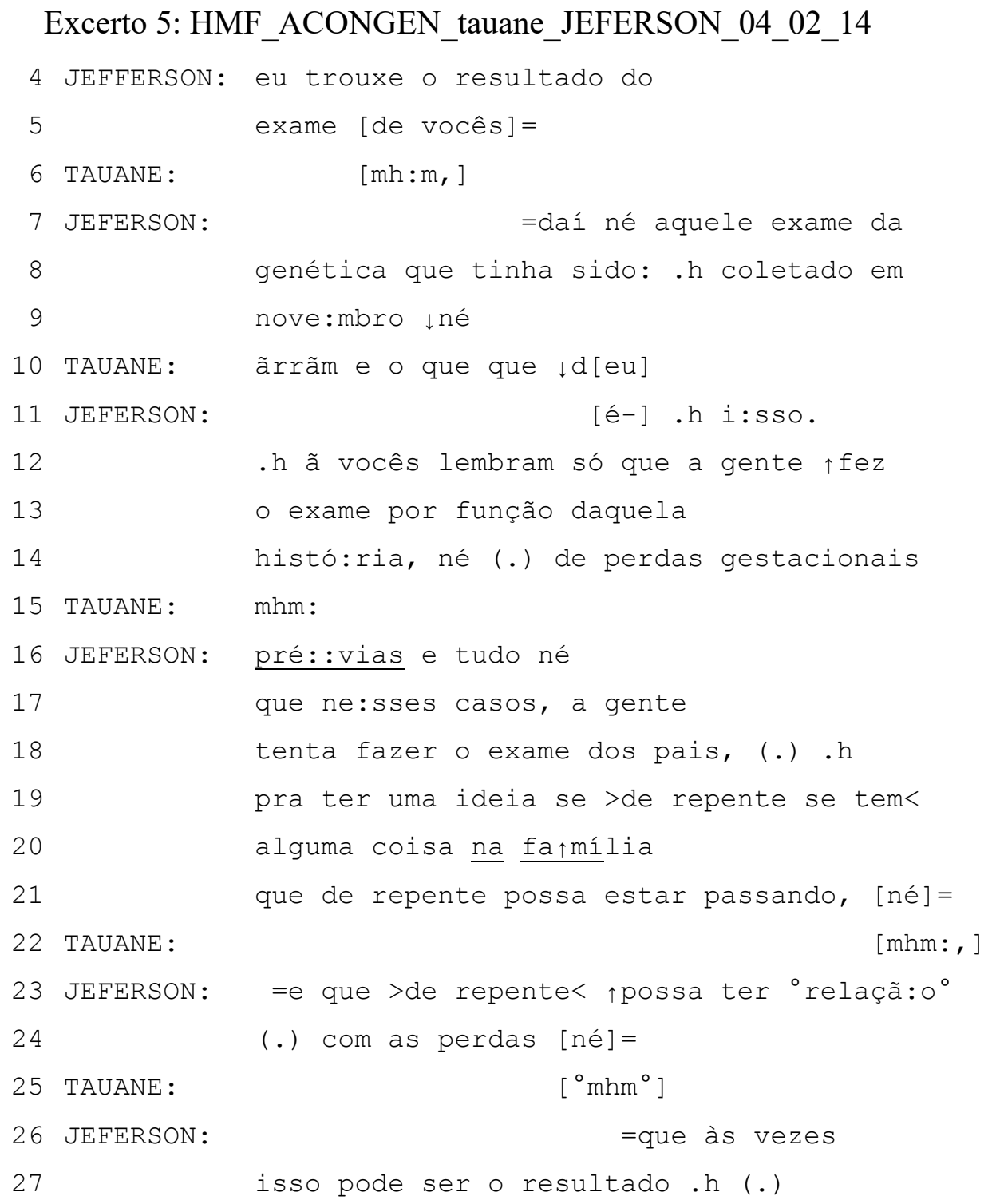


28

29 TAUANE :

30 JEFERSON :

32 TAUANE :

33 JEFERSON :

34 TAUANE :

35 JEFERSON :

50 TAUANE :

51 JEEERSON :

52

53 TAUANE :

54 JEFERSON :

55

56

57

58 ACOMPA. :

59 JEFERSON :

60

61 TAUANE : de alguma coisa: da família [tá]=

$\left[{ }^{\circ} \mathrm{mhm}:{ }^{\circ}\right]$

=mas a avaliação de vocês veio:

nor $\uparrow$ mal [tá veio-]=

$[\underline{A H}$ tá $]$

=veio boa tá

$\left\{\{\right.$ rindo $\}<^{\circ}$ tá bom $\left.^{\circ}>\right\}=$

$=. h$ então ã essa avaliação

dos cromossomos a gente $\{\{$ sorrindo\} não

identificou nenhuma alteração [ ttá\}]

[tá: ]

. h é que a gente tava preocupado a-

até em função da: gestação

atual, .h porque dependendo do

resultado, a gente: >haveria de repente<

(.) indicação de: fazer

a avaliação $\uparrow$ no bebê

$\mathrm{m} \uparrow \mathrm{hm}:::=$

=né . h mas o exame

vindo norma:l, e eu tava

revisando aqui os exames

do bebê tem vindo todos $\uparrow$ bons [né ] =

[mhm ]

=a morfoló::gica, (.) a avaliação

do coração, [né ]=

[sim]

=então isso: : é

um: : (.) >ponto bem< positivo

que tá indicando parece

que tá indo tudo:=

=ai que bom=

=tudo

tranquilo $[\{\{r i n d o\}$ né $\}]$

[tá: . ]

A sequência de comunicação de notícias é iniciada logo após os cumprimentos iniciais. Nas linhas 4-5 e 7-9, o geneticista pré-anuncia que tem notícias sobre o resultado do exame. Na linha 10, a gestante solicita o resultado dos cariótipos por meio de uma pergunta. Em adjacência e parcialmente em sobreposição à solicitação da gestante, o médico confirma ("[é ] .h i : sso."). Contudo, a pergunta da gestante fora aberta (1. 10); 
ou seja, há, aqui, um desalinhamento à relevância condicional gerada pela primeira parte do par adjacente solicitação de informação-provimento de informação. Essa prática adia a comunicação da notícia propriamente dita, violando, assim, a preferência pela contiguidade da interação gerada a partir da primeira parte do par adjacente (i.e. solicitação) (SACKS, 1987; SCHEGLOFF, 2007), e permite ao médico fazer a retomada dos fatos que motivaram a indicação da análise do cariótipo do casal (i.e. histórico de perdas gestacionais e sua possível associação a alguma anomalia hereditária). Por meio de um pedido de confirmação "vocês lembram só que a gente" (1. 12), Jeferson informa e justifica que, antes de anunciar o resultado do exame, vai "só" (primeira e rapidamente) fazer uma retomada dos procedimentos realizados com o casal até o momento. Ao longo dessa retomada, que se caracteriza como uma breve narrativa, a gestante oferece apenas continuadores "mhm" (1. 22, 25 e 29), o que oportuniza ao profissional amplo espaço de fala.

Como havia probabilidade de que existisse uma anomalia nos cariótipos do casal, a retomada de Jeferson presta conta das razões que motivaram a investigação via exame. Essa busca por uma provável anomalia (e sua relação com o histórico de perdas) é especialmente evidenciada pelo uso da conjunção adversativa "mas" no anúncio da boa notícia de que o resultado da avaliação do casal viera "nor ^mal" (1. 30-31), i.e., o médico introduz a notícia como sendo uma informação que "não" confirma nem a anomalia, nem a possível relação com as perdas.

Ao anunciar as boas notícias sobre o resultado dos cariótipos (1. 30-31), o par adjacente solicitação por notícias-comunicação da notícia (iniciado na linha 10 pela gestante) é finalmente fechado. Assim que Jeferson termina a primeira "unidade de construção de turno" ( $\mathrm{UCT}^{17}$ ), a gestante produz um recibo de notícias (" [ $\underline{\mathrm{AH}}$ tá] ", 1. 32) em fala sobreposta à segunda UCT do médico.

$\mathrm{Na}$ linha 34, a gestante oferece outro recibo de informação " $\left\{\{\right.$ rindo $\}<{ }^{\circ}$ tá bom $^{\circ}>$ \}", que poderia ter sido tomado por Jeferson como uma tentativa de pré-fechamento da consulta. No entanto, a partir da linha 35, o geneticista elabora o significado do resultado, mostrando uma perspectiva positiva: não será necessário fazer a avaliação dos cromossomos do bebê. Essa perspectiva positiva culmina nas linhas 54-57 e 58-59, quando o médico exibe declaradamente uma avaliação positiva da situação do casal e do feto.

Assim, até a linha 57, Jeferson parece se engajar numa prática de explicação para que gestante (e acompanhante) saibam como interpretar o resultado: as razões pelas quais ele deve ser entendido como algo positivo. O médico encerra a elaboração do significado da notícia apenas quando recebe uma avaliação positiva da gestante ("ai que bom”, 1 . 58), ao que ele responde com outra avaliação positiva: “tudo tranquilo [ \{ \{rindo\} né \} ]" (1. 59-60), que propõe o fechamento da sequência de comunicação de notícias.

\footnotetext{
${ }^{17}$ Os turnos de fala contêm pelo menos uma unidade de construção de turno (também referida como UCT), i.e., uma contribuição de fala que tem "início, meio e fim bem definidos" (WATSON; GASTALDO, 2015 , p. 102). Contudo, as UCTs não são determinadas por sua classe gramatical apenas, mas por sua adequação e completude, o que lhes é atribuído pelos/as próprios/as participantes, com base em seu formato sintático, entoacional, semântico-pragmático e em sua posição sequencial. As UCTs também projetam um local possível para a troca de falantes..
} 
Maynard (2003) aponta que boas notícias tendem a ser anunciadas imediatamente na interação. A análise do Excerto 5, diferentemente disso, revela que o médico préanuncia a notícia, porém, antes de anunciá-la, primeiramente realiza uma retomada dos procedimentos realizados no hospital, justificando-os. Essa retomada, mesmo que breve, permite que a gestante e seu companheiro tenham acesso ao raciocínio médico utilizado para realização dos procedimentos aos quais foram submetidos. Ainda, a retomada parece também agir como uma espécie de prestação de contas sobre o fato de indicar exames que, ao final, tiveram resultado normal.

O AG de onde advém o Excerto 6, a seguir, refere-se à comunicação do diagnóstico de Síndrome de Down. Dada a natureza da notícia e, em especial, o quadro depressivo da gestante relatado por ela própria na consulta anterior, Jeferson requisita a presença da psicóloga para a consulta em questão. O marido da gestante também está presente nessa consulta.

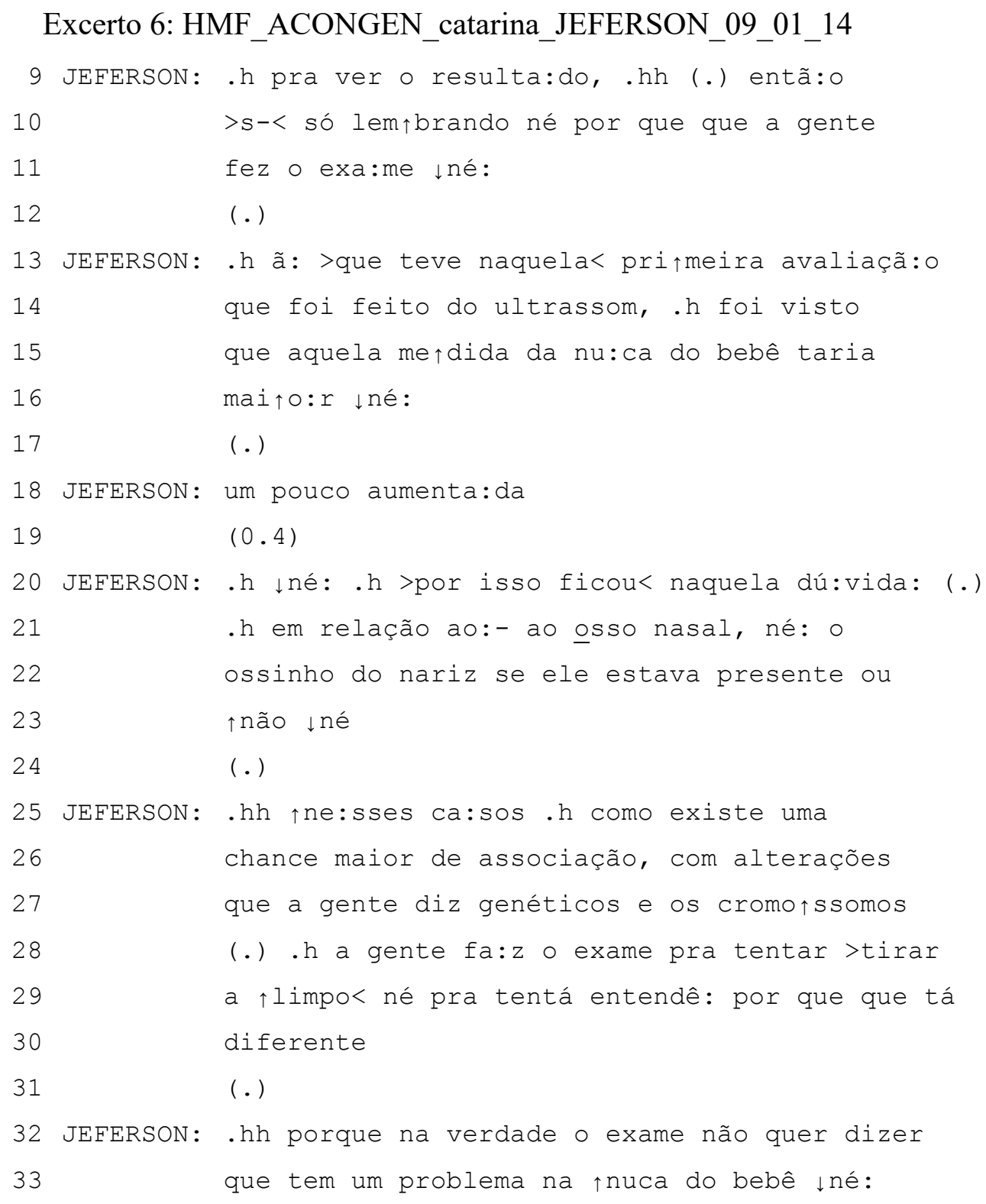


34

55 JEFERSON :

56 CATARINA:

57 JEFERSON :

58 CATARINA:

61

64 JEFERSON :

72 JEFERSON :

CATARINA:

(.)

.h mas na verdade ele pode se:r indicativo de alıguma outra coisa difere:nte que possa tá acontece:ndo, (.) .h com o bebê: né:,

(.)

.hh e:: nesse meio tempo também foi feita a ecocardiografi:a ontem $\uparrow$ né

(.)

.hh que daí: (evidenciou >novamente<) que teria alguma ateração no coração do bebê: né, $(0.4)$

JEFERSON: .h a doutora luana falou com você:s daí né, explico:u, $(0.7)$

.h o que que vocês entenderam gente.

$$
\text { (.) }
$$

assim (.) do exame ontem.= $=. h h h$ eu fiquei em choque

ontem e eu não consegui conversar e eu sou $[$ sempre $]=$ [sim] =che:ia de questiona[e:ntos]

$$
\text { [si:m] sim= }
$$

$=\mathrm{mas}$

não não consegui conver $\uparrow$ sar

(. )

JEFERSON: $\operatorname{si}\left[\mathrm{m} \operatorname{sim}\left({ }^{\circ} \mathrm{sim}^{\circ}.\right)\right]$

CATARINA: [.hh mas eu] já- eu $\uparrow$ sei o que é: mais ou menos assim eu sei que: [todos]= [sim]

=nós temos duas válvulas, o nenê na verdade teve $\uparrow u-(0.4)$ a: das duas dele (.) acabou se fundi:ndo e se formou só $\uparrow$ uma . hh

JEFERSON : ã [rrã ]

CATARINA: [O QU]E não vai dá: a vasão que ele precisa pra qua:ndo $\left[>0-u-e^{-<}\right]=$ $\left[{ }^{\circ} \mathrm{sim}^{\circ} \cdot\right]$

OSTERMANN, Ana Cristina; FREZZA, Minéia. "Veio o resultado do exame": a comunicação de notícias diagnósticas (e como investigações linguístico-interacionais podem informar as práticas profissionais). Linguagem em (Dis)curso - LemD, Tubarão, SC, v. 17, n. 1, p. 25-50, jan./abr. 2017. 
73 CATARINA:

75 JEFERSON :

76 CATARINA:

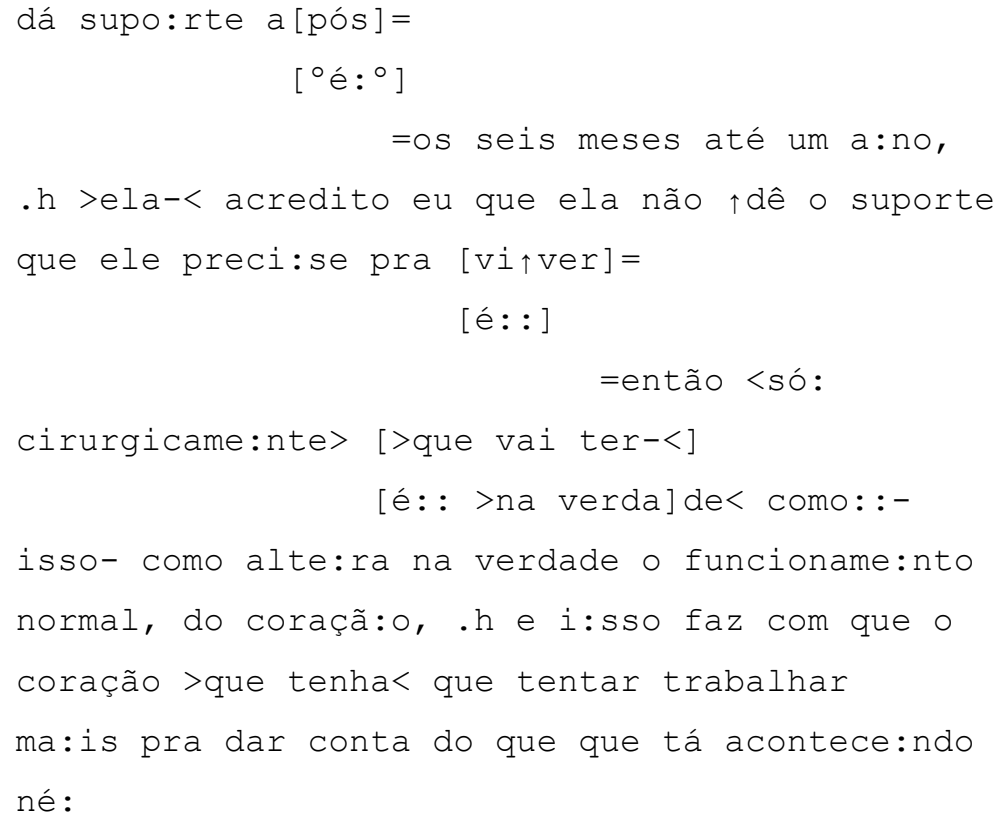

Antes de anunciar o resultado do cariótipo fetal (pré-anunciado nas linhas 2-7 do Excerto 4), o geneticista retoma os motivos que justificam a indicação do exame:

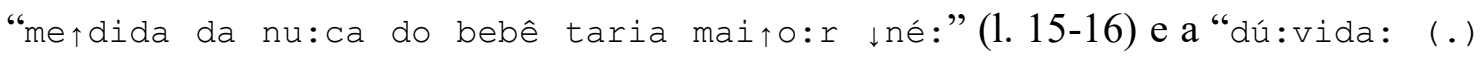
.h em relação ao:- ao osso nasal," (1. 20-21). Outro motivo que justificara o exame fora a identificação de uma cardiopatia, fato esse também retomado Jeferson (1. $39-43)$.

Nas linhas 46-47, Jeferson solicita a confirmação de que Luana, a ecocardiografista, havia falado com o casal. Depois de uma pausa, nas linhas 49-51, o médico solicita a "apresentação de perspectiva" do casal (KANG; ZAYTS, 2010; MAYNARD, 1992) i.e. seu entendimento do que a médica ecocardiografista explicara. Com base no que Catarina apresenta de seu entendimento do que lhe fora explicado (1. 52-81), Jeferson provê mais informações sobre uma possível cirurgia para correção da malformação cardíaca do bebê (1. 82 em diante). Observe-se que a ação de solicitar a perspectiva das gestantes e de seus/suas acompanhantes se repete em 11 das 18 interações analisadas neste estudo. Essa recorrência revela a orientação do profissional para oferecer informações que sejam adequadas ao que seus/suas cointeragentes já sabem a respeito da situação. A ação de solicitar a perspectiva oportuniza a verbalização do entendimento e da avaliação da situação (do feto ou da gravidez) que paciente e acompanhantes estão fazendo. Ao ter acesso a esses entendimentos e avaliações, o/a profissional de saúde pode oferecer informações mais ajustadas ou particularizadas aos/as seus/suas interagentes. Além disso, a apresentação de perspectiva pode auxiliar num trabalho interacional mais compartilhado de comunicação da notícia entre médico/a e paciente.

O Excerto 7 advém da mesma consulta apresentada nos Excertos 4 e 6 e apresenta o fechamento da retomada e o anúncio propriamente dito da má notícia: 


\section{Excerto 7: HMF_ACONGEN_catarina_JEFERSON_09_01_14}

113 JEFERSON: .hh >então na verdade< (1.1) †isso

114

115

116

117

118

119

120

121 CATARINA:

122

123

124 JEFERSON:

125 CATARINA:

126

127 JEFERSON:

130 CATARINA:

131 JEFERSON :

134 JEFERSON:

137

141 CATARINA:

142

143 JEFERSON:

144 CATARINA:

145

146 JEFERSON:

147 CATARINA:

148

149 JEFERSON: é:=

150 CATARINA: =parecer favorável a ${ }^{\circ}$ nós ${ }^{\circ}$.

que a gente [tinha]=

[é: : ]

[ent] $\tilde{a}:: 0,=$

$\mathrm{f}:$ : corro[bora $\uparrow q u e-]$

[ma: is ]

a mais acontece:ndo né:

(.)

né ((psicóloga tosse))

(.)

porque tinha já si[na:is]

no fu:ndo [no nosso cora] ção=

[precoces.]

já sabe que ${ }^{\circ}$ não ${ }^{\circ}$.

Sim

$(0.8)$ 'é:: ${ }^{\circ}$ de certa forma: ${ }^{\circ} f-f-{ }^{\circ}$ foi então

- se१gundo exame que foi feito né

que foi específico .h $\uparrow$ do coração, .h e

que .h além de terem sido vi:stas

aquelas poutras alterações (.) ${ }^{\circ}$ né do- ${ }^{\circ}$ do

osso nasal, e da $\uparrow$ nuca .h foi visto

também essa alteração [do- do coraçã:o né]

[é: e o que tirou †toda]

e qualque:r (.) e qualquer ã expectativa

[ $\left.\uparrow e^{-}\right] \quad=e ́->$ na verdade $<\circ$ que que

acontece (.) é:: tipo: (.) ã: †isso

exatamente que †tenha alguma coisa

.h e por i:sso a importância da

realização do exa:me esse do cariótipo

.hh então nós fizemos nesse sen†tido né

de tenta:r entender o que que tava acontece:ndo

[mas a] gente já:

$=a$ gente

que a gente não tem chance de $u: m$

OSTERMANN, Ana Cristina; FREZZA, Minéia. "Veio o resultado do exame": a comunicação de notícias diagnósticas (e como investigações linguístico-interacionais podem informar as práticas profissionais). Linguagem em (Dis)curso - LemD, Tubarão, SC, v. 17, n. 1, p. 25-50, jan./abr. 2017. 


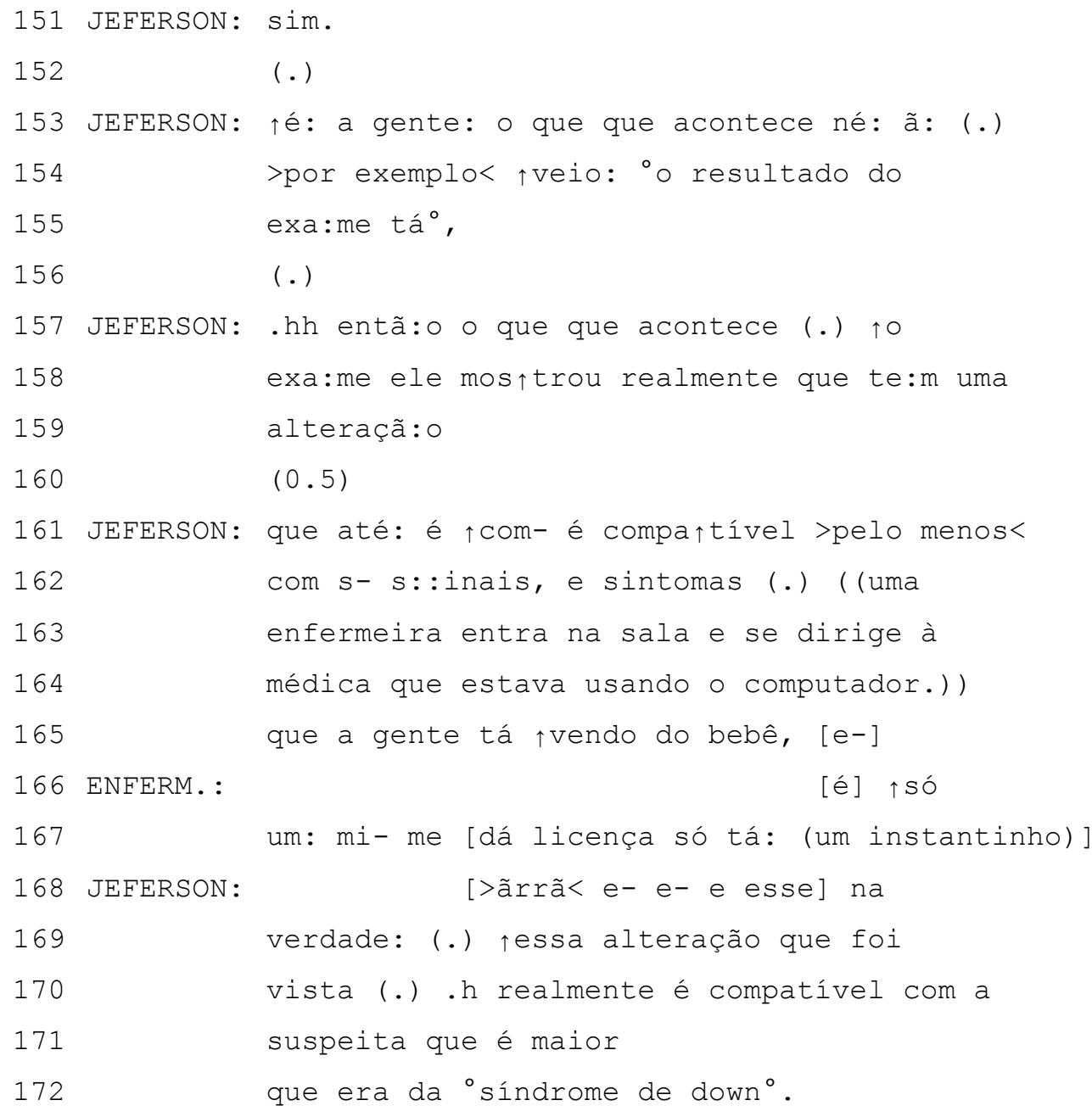

Nas linhas 113-20, o médico faz o fechamento da retomada das pistas que compõem o diagnóstico a ser entregue. Quando Jeferson repete, nas linhas 119-120, que "foi vis to também essa alteração [do- do coraçã:o né]", Catarina avalia o significado das informações providas por Jeferson como características para o diagnóstico de Síndrome de Down (1. 121-23 e 125-26), com o que Jeferson concorda (1. 127-29 e 131-32). Ainda que Catarina tenha, de certa forma, antecipado a notícia, Jeferson atrasa o seu anúncio ao usar o referente indefinido "alguma coisa" (1.131) em vez de anunciar o diagnóstico. Nas linhas 134-40, Jeferson justifica a realização do cariótipo fetal para entender a origem das características que o feto apresenta, e a gestante oferece mais uma avaliação sobre o que as evidências apontam, antecipando mais uma vez a notícia diagnóstica (1. 141-42, $144-45,147,150)$.

Nas linhas 154-55, Jeferson retoma o pré-anúncio que fizera no início da interação (1. 5 do Excerto 4), sobre a chegada do resultado do exame. Em seguida, ao utilizar o advérbio de afirmação "realmente" (1. 157-59), Jeferson sela a ação de concordar com a avaliação que Catarina fizera nas linhas anteriores. Nas linhas 161-62, ele inicia a ação de comunicar o diagnóstico - interrompida brevemente quando uma enfermeira entra na sala -, anunciando que, de fato, a alteração encontrada no cariótipo fetal é compatível com o diagnóstico de Síndrome de Down (1. 168-172). 
O trabalho interacional do geneticista é, assim, em certa medida, facilitado nessa interação, já que ele não precisa anunciar (em primeira posição), mas apenas concordar (em segunda posição) com a avaliação diagnóstica provida pela gestante. Em outras palavras, em vez de um par adjacente anúncio (pelo médico)-recibo de anúncio (pela gestante), acontece um par adjacente avaliação da condição do feto (pela gestante)concordância com a avaliação (pelo médico).

A seguir, apresentamos trechos da fala de Jeferson retirados da retomada que antecede o anúncio da má notícia nos Excertos 6 e 7.

(1) .h ã: >que teve naquela< pri†meira avaliaçã:o

que foi feito do ultrassom, .h foi visto

que aquela me $\uparrow$ dida da nu:ca do bebê taria

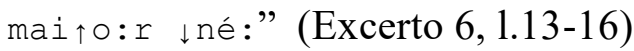

(2) . hh >então na verdade< (1.1) 个isso

○é:: ${ }^{\circ}$ de certa forma: ${ }^{\circ} f-f-{ }^{\circ}$ foi então

o se $\uparrow$ gundo exame que foi feito né

que foi específico .h $\uparrow$ do coração, .h e

que. h além de terem sido vi:stas

aquelas $\uparrow$ outras alterações (.) ' ${ }^{\circ}$ é do- ${ }^{\circ}$ do

osso nasal, e da $\uparrow$ nuca .h foi visto

também essa alteração [do- do coraçã:o né] (Excerto 7, 1.113-20)

(3) .hh e:: nesse meio tempo também foi

feita a ecocardiografi:a ontem $\uparrow$ né

(.)

.hh que daí: (evidenciou >novamente<) que

teria alguma ateração no coração do bebê: (Excerto 6, 1. 39-43)

(4) >por exemplo< $\uparrow$ veio: ${ }^{\circ} \circ$ resultado do

exa:me tá, (Excerto 7, 1. 154-55)

(5) .hh entã: o o que que acontece (.) १o

exa:me ele mos $\uparrow$ trou realmente que te:m uma

alteraçã:o

$(0.5)$

que até: é $\uparrow$ com- é compa $\uparrow$ tível >pelo menos<

com s- s::inais, e sintomas (.)

que a gente tá †vendo do bebê, [e-]

na verdade: (.) †essa alteração que foi 


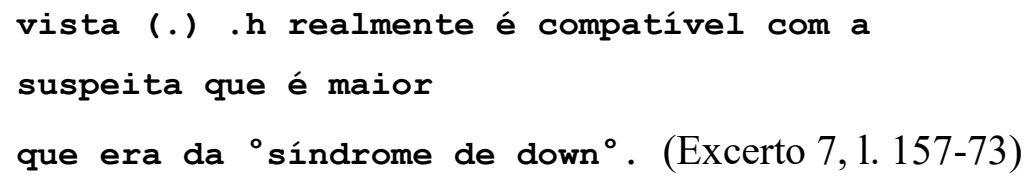

Os exemplos 1 a 3 apresentam informações que auxiliam na construção do diagnóstico: "os exames que foram feitos" e "as alterações que foram vistas", construídos na voz passiva, sem a presença dos agentes que realizaram as ações de "ver" e "fazer os exames" - a saber, os/as profissionais que compõem a equipe de medicina fetal. Ainda, os exames ocupam a posição de agentes da ação de "mostrar uma alteração" (exemplo 6) e as alterações ocupam a posição de agentes da ação de "vir compatível com Síndrome de Down" (exemplo 5).

Assim, no caso de más notícias, dois processos distanciam as pessoas envolvidas na comunicação e no recebimento da notícia: (1) despessoalização e desinstitucionalização da comunicação de má notícia, que é anunciada pelo "exame que vem alterado" e não pelo profissional ("eu") nem pela equipe médica ("a gente") que "traz o resultado" e (2) a despessoalização da doença (DEL VENTO et al., 2009), por meio da qual a doença é anunciada sem que os fetos sejam apresentados como os portadores das alterações (e.g. há uma alteração vs. o feto tem uma alteração).

Já na comunicação de boas notícias, a característica de normalidade é "pessoalizada", como se vê a seguir:

(8) a avaliação de vocês veio normal (Excerto 5, 1. 30-31).

(9) a gente vê <uma menina: :> nor $\uparrow$ mal

(HMF_ACONGEN_edineia_JEFERSON_28_01_14 - não discutido no artigo, 1.56)

A preposição "de" utilizada no turno do exemplo 8 estabelece uma relação entre a avaliação, os progenitores - "vocês" - e a característica de "normalidade". Aqui, a normalidade tem uma referência humana: os progenitores. O turno do exemplo 9 apresenta o adjetivo "normal" utilizado como qualificador do feto: uma menina normal. Os processos de pessoalização da normalidade e de despessoalização da anormalidade se mostram como prática recorrente nos dados. 
A análise revela que, antes de ser provida a notícia diagnóstica (boa ou ruim), há primeiro uma orientação para explicações às pacientes (e acompanhantes) para que compreendam como esse resultado foi alcançado, uma espécie de sequência "pedagógica" que se dá, principalmente, por meio de retomadas. As retomadas se assemelham ao processo de antecipação de más notícias descrito por Schegloff (1988) e Maynard (1996), já que oferecem pistas sobre as notícias que estão por vir e, assim, propiciam que as pacientes as anunciem antes mesmo de o profissional fazê-lo, como observado no Excerto 7. Esse processo, de certa forma, facilita o trabalho interacional de quem porta as notícias, já que o anúncio da notícia acontece em segunda posição: a paciente oferece uma avaliação diagnóstica do que as informações oferecidas na retomada significam (primeira parte do par adjacente), que demanda apenas uma concordância (ou discordância) do profissional (segunda parte do par adjacente), confirmando, assim, (ou não) a interpretação da paciente.

Os dados apontam a recorrência da chamada "série de apresentação de perspectiva" (KANG; ZAYTS, 2010; MAYNARD, 1992). Essa prática, que permite ao médico ter acesso ao que a paciente e acompanhante(s) já sabem, como avaliam ou o que esperam em relação ao caso em questão, oportuniza o provimento de informações ajustadas aos/às interagentes e particularizadas a cada caso. Ademais, ao solicitar as perspectivas das figuras afetadas, o médico pode identificar as expectativas das famílias e oferecer auxílio psicológico no próprio hospital, caso seja necessário.

Ao longo da análise de dados, observamos que o médico se posiciona de diferentes formas quanto ao papel de portador de notícias. Quando a valência das notícias é ruim, os exames adquirem características animadas e recebem a agência de trazer ou de portar a má notícia; ou seja, é omitido o agente humano das ações de "trazer" ou de "comunicar" a má notícia por meio dos processos de desinstitucionalização e de despessoalização. Por outro lado, as sequências de comunicação de boas notícias são pessoalizadas e institucionalizadas, pois a posição de agente do pré-anúncio e/ou do anúncio dessas notícias tende a ser ocupada pelo pronome pessoal na primeira pessoa do singular ou pela locução pronominal "a gente".

Semelhante ao processo de desinstitucionalização e despessoalização da entrega de más notícias, o processo de "despessoalização da doença" (DEL VENTO et al., 2009; GILL; MAYNARD, 1995) é outra prática observada nos dados, que trata da tendência de apresentar a doença sem utilizar referentes pessoais. Em outras palavras, o feto apresenta uma doença, mas essa doença é anunciada como descolada dele.

Os pré-anúncios, as retomadas, as séries de apresentação de perspectiva e as justificativas de realização de exames funcionam como uma grande pré-sequência que prepara as pacientes para o que vem a seguir: o anúncio de uma notícia ruim. Em nossos dados, as figuras afetadas participam e são convidadas a participar da construção do entendimento acerca das notícias diagnósticas sobre seus/suas filhos/as, facilitando, assim, o trabalho do profissional, que, interacionalmente, não atua sozinho na comunicação de uma má notícia diagnóstica, mas coconstrói e compartilha essa atividade com a gestante e acompanhante(s). 
BAILE, W. K. et al. SPIKES - A six-step protocol for delivering bad news: application to the patient with cancer. The Oncologist, [S.1.], v. 5, n. 4, p. 302-311, 2000. Disponível em: <www.theoncologist.com>. Acesso em: 15 nov. 2012.

BRUNONI, D. Aconselhamento genético. Ciência \& Saúde Coletiva, Rio de Janeiro, v. 7, n.1, p. 101107, 2002. Acesso em: 15 fev. 2014. Disponível em: <http://www.scielo.br/

scielo.php?script=sci_arttext\&pid=S151684842002000400002\&lng=pt\&nrm=iso]>. Acesso em: 15 dez. 2014.

BUCKMAN, R. Breaking bad news: why is it still so difficult?. British Medical Journal, [S.1], v. 288, p. 1597-1599, 1984.

CUNHA, A. M. F. V.; BLASCOVI-ASSIS, S. M.; FIAMENGHI, G. A. Jr. Impacto da notícia da Síndrome de Down para os pais: histórias de vida. Ciência \& Saúde Coletiva, Rio de Janeiro, v. 15, n. 2 , p. 445-451, 2010.

DEL VENTO, A. et al. An experimental investigation of the dilemma of delivering bad news. Patient Education and Counseling, [S.1.], v. 77, p. 443-449, 2009.

DREW, P.; HERITAGE, J. Talk at work: interaction in institutional settings. Cambridge: Cambridge University, 1992.

FALLOWFIELD, L.; JENKINS, V. Communicating sad, bad, and difficult news in medicine. The Lancet, [S.1.], v. 363, p. 312-319, 2004.

FREESE, J.; MAYNARD, D. W. Prosodic features of bad news and good news in conversation. Language in Society, [S.1.], v. 27, p. 195-219, 1998.

GILL, V. T.; MAYNARD, D. On 'labeling' in actual interaction: delivering and receiving diagnoses of developmental disabilities. Social Problems, [S.1.], v. 42, p. 11-37, 1995.

GIRGIS, A.; SANSON-FISHER, R. W. Breaking bad news: consensus guidelines for medical practitioners. Journal of Clinical Oncology, [S.1.], v. 13, n. 9, p. 2449-2456, 1995.

GOMES, A. G.; PICCININI, C. A. Malformação no bebê e maternidade: aspectos teóricos e clínicos. Psicologia Clínica, Rio de Janeiro, v. 22, n. 1, p. 15-38, 2010.

HEATH, C. The delivery and reception of diagnosis in the general-practice consultation. In: DREW, P.; HERITAGE, J. (Ed.). Talk at work: interaction in institutional settings. Cambridge: Cambridge University Press, 1992. p. 235-267.

HERITAGE, J. The epistemic engine: sequence organization and territories of knowledge. Research on Language \& Social Interaction, v. 45, n.1, p.30-52, 2012.

INSTITUTO NACIONAL DE CÂNCER (INCA). Coordenação Geral de Gestão Assistencial. Coordenação de Educação. Comunicação de notícias difíceis: compartilhando desafios na atenção à saúde. Rio de Janeiro: INCA, 2010. Disponível em:

$<$ http://bvsms.saude.gov.br/bvs/publicacoes/comunicacao_noticias_dificeis.pdf $>$. Acesso em: 10 jan. 2013.

JEFFERSON, G. Transcript notation. In: ATKINSON, J. Maxwell; HERITAGE, J. Structures of social action: studies in conversation analysis. New York: Cambridge University Press, 1984. p. ix-xvi.

KANG, M. A.; ZAYTS, O. Information delivery in prenatal genetic counseling: on the role of initial inquiries. Journal of Asian Pacific Communication, [S.1.], v. 20, n. 2, p. 243-259, 2010.

MAYNARD, D. W. “Does it mean I'm gonna die?'”: on meaning assessment in the delivery of diagnostic news. Social Science \& Medicine, [S.1.], v. 62, p. 1902-1916, 2006.

Bad news, good news: conversational order in everyday talk and clinical settings. Chicago: The

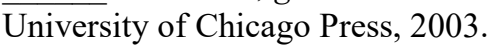

The news delivery sequence: bad news and good news in conversational interaction. Research on Language and Social Interaction, [S.1.], v. 30, p. 93-130, 1997.

On "realization" in everyday life: the forecasting of bad news as a social relation. AmericanSociological Review, [S.1.], v. 61, p. 109-131, 1996.

On clinicians co-implicating recipients' perspective in the delivery of diagnostic news. In: DREW, P.; HERITAGE, J. (Ed.). Talk at work: interaction in institutional settings. Cambridge: Cambridge University Press, 1992. p. 331-358. 
Notes on the delivery and reception of diagnostic news regarding mental disabilities. In: HELM, David T. et al. (Ed.). The interactional order: new directions in the study of social order. NewYork: Irvington Publishers. 1989. p. 54-67.

; FRANKEL, R. M. On diagnostic rationality: bad news, good news, and the symptom residue. In: HERITAGE, J.; MAYNARD, D. W. (Ed.). Communication in medical care: interaction between primary care physicians and patients. Cambridge: Cambridge University Press, 2006. p. 248-278.

OSTERMANN, A. C. Uma mulher, um feto, e uma má notícia: a entrega de diagnósticos de síndromes e de malformações fetais - em busca de uma melhor compreensão do que está por vir e do que pode ser feito. 2013-atual. São Leopoldo, 2013. Projeto de Pesquisa financiada pelo CNPq.

. Análise da conversa: o estudo da fala-em-interação. In: OSTERMANN, A. C.; MENEGHEL, S. (Org.). Humanização. Gênero. Poder: contribuições dos estudos de fala-em-interação para a atenção à saúde. Rio de Janeiro e Campinas: Fiocruz: Mercado de Letras, 2012. p. 33-43.

; SOUZA, J. As demandas interacionais das ligações para o Disque Saúde e sua relação com o trabalho prescrito. Alfa: Revista de Linguística (UNESP. São José do Rio Preto. Impresso), v. 55, p. 135 162, 2011. Disponível em: <http://seer.fclar.unesp. br/alfa/article/view/4171/3769>. Acesso em: 10 jan. 2013.

PERÄKYLÄ, A. Communicatin and responding to diagnosis. In: HERITAGE, J.; MAYNARD, D. W. (Ed.). Communication in medical care: interaction between primary care physicians and patients. Cambridge: Cambridge University Press, 2006. p. 214-247.

PINA-NETO, J. M. Genetic counseling. Jornal de Pediatria, Rio de Janeiro, v. 84, n. 4, p. 20-26, 2008. REED, S. C. Counseling in medical genetics. Phyladelphia/London: W. B. Soundres Company, 1955.

SACKS, H. Pronouns. In: JEFFERSON, G. (Ed.). Lectures on Conversation. Oxford: Blackwell, 1992. v. 1, p. 711-715.

On the preference for agreement and contiguity in sequences in conversation. In: BUTTON, G.; LEE, J. R. E. (Ed.). Talk and social organization. Clevedon: Multilingual Matters, 1987. p. 54-69.

; SCHEGLOFF; E.; JEFFERSON, G. A simplest systematics for the organization of turn taking for conversation. Language, Studies in the Organization of Conversational Interaction, New York, v. 50, n. 4, p. 696-735, 1974.

SCHEGLOFF, E. Sequence organization in interaction: a primer in conversation analysis. Cambridge: Cambridge University Press, 2007.

On an actual virtual servo-mechanism for guessing bad news. Social Problems, [S.1.], v. 35, n. 4 , p. 442-457, 1988.

SELTING, M.; et al. A system for transcribing talk-in-interaction: GAT2 translated and adapted for English by Elizabeth Couper-Kuhlen and Dagmar Barth-Weingarten, 2011. Disponível em: $<$ http://www.gespraechsforschung-ozs.de/heft2011/px-gat2-englisch.pdf>. Acesso em: 12 fev. 2013 SOUZA, J.; OSTERMANN, A. C. Glossário conciso de termos de estudos de fala-em-interação. In: OSTERMANN, A. C.; MENEGHEL, S. (Org.). Humanização. Gênero. Poder: contribuições dos estudos de fala-em-interação para a atenção à saúde. Rio de Janeiro e Campinas: Fiocruz: Mercado de Letras, 2012. p. 163- 165.

WATSON, R.; GASTALDO, E. Etnometodologia e Análise da Conversa. Petrópolis, RJ: Vozes; Rio de Janeiro: Editora PUC-Rio, 2015.

ANEXO - CONVENÇÕES DE TRANSCRIÇÃO

\begin{tabular}{|l|l|}
\hline$(1.8)$ & Pausa \\
\hline$()$. & Micropausa \\
\hline$=$ & Fala colada \\
\hline$[$ Texto $]$ & Falas sobrepostas \\
\hline, & Entonação contínua \\
\hline$\uparrow$ texto & Entonação ascendente da sílaba \\
\hline$\downarrow$ texto & Entonação descendente da sílaba \\
\hline
\end{tabular}

OSTERMANN, Ana Cristina; FREZZA, Minéia. "Veio o resultado do exame”: a comunicação de notícias diagnósticas (e como investigações linguístico-interacionais podem informar as práticas profissionais). Linguagem em (Dis)curso - LemD, Tubarão, SC, v. 17, n. 1, p. 25-50, jan./abr. 2017. 


\begin{tabular}{|l|l|}
\hline$\cdot$ & Entonação descendente do turno \\
\hline$?$ & Entonação ascendente do turno \\
\hline- & Marca de interrupção abrupta da fala \\
\hline$:::$ & Alongamento de som \\
\hline$>$ Texto $<$ & Fala acelerada \\
\hline$>>$ Texto $<<$ & Fala muito acelerada \\
\hline$<$ Texto $>$ & Fala mais lenta \\
\hline$<<$ Texto $>>$ & Fala muito mais lenta \\
\hline TEXTO & Fala com volume mais alto \\
\hline${ }^{\circ}$ texto $^{\circ}$ & Volume baixo \\
\hline${ }^{\circ}{ }^{\text {texto }}{ }^{\circ 0}$ & Volume muito baixo \\
\hline Texto & Sílaba, palavra ou som acentuado \\
\hline$($ Texto $)$ & Dúvidas da transcritora \\
\hline xxxx & Fala inaudível \\
\hline$(($ Texto $)$ & Comentários da transcritora \\
\hline hhhh & Riso expirado \\
\hline hahahehehihi & Risada com som de vogal \\
\hline$\{\{$ rindo $\}$ texto $\}$ & Turnos ou palavras pronunciadas rindo \\
\hline hhh & Inspiração audível \\
\hline
\end{tabular}

Agradecemos ao CNPq e à FAPERGS pelo apoio obtido através de Bolsa de Produtividade em Pesquisa (Processo CNPq n. ${ }^{\circ}$ 311473/2012-1) e pelos auxílios-pesquisa obtidos por meio dos editais MCTI/CNPq/SPM-PR/MDA 32/2012 (Processo n. ${ }^{\circ}$ 405154/2012-7), MCTI/CNPq/MEC/CAPES 43/2013 (Processo n. ${ }^{\circ}$ 406012/2013-0) e PPSUS FAPERGS/MS/CNPq/SESRS 02/2013 (Processo n. ${ }^{\circ}$ 1259-2551-13-3) à primeira autora, e também à CAPES pelo apoio obtido por meio de bolsa de Doutorado concedida à segunda autora.

Recebido em: 12/02/16. Aprovado em: 30/08/16.

Title: "The result of the exam came": diagnostic news delivery (and how linguistic-interactional investigations can inform professional practices)

Authors: Ana Cristina Ostermann; Minéia Frezza.

Abstract: Based on the principles offered by ethnomethodological Conversation Analysis, this article describes the delivery of diagnostic news in 54 audio-recorded genetic counseling consultations that happened in a public hospital ward in Brazil (Sistema Único de Saúde, SUS) specialized in moderate and high risk pregnancies. All recorded consultations were fully transcribed, but for the purposes of this study only the 18 interactions that contained diagnostic news delivery sequences were analyzed, regarding to the actions that make up such sequences. The data analysis shows that the news delivery sequence (NDS) bears characteristics of some type of pedagogical sequence that benefits the joint meaning making of the diagnosis and the coconstruction of the news itself, a task that is shared between doctor and patient. In the delivery of bad news, in particular, the processes of agentivity of the test and of disease depersonalization are identified. The study describes different linguistic-interactional practices used to deal with participants' distress and that might be used to subsidize health professionals' trainings to whom diagnosis delivery constitutes an everyday event.

Keywords: Genetic counseling. News delivery. Pedagogical sequence. Agentivity. 
Título: "Llegó el resultado de la revisión médica": la comunicación de noticias diagnósticas (y como investigaciones lingüístico-interacionales pueden informar las prácticas profesionales)

Autores: Ana Cristina Ostermann; Minéia Frezza

Resumen: Este artículo describe, desde el Análisis de la Conversación de base etnometodológica, la comunicación de noticias diagnósticas en 54 consultas de asesoramiento genético registradas en audio en un sector del hospital materno-infantil del Sistema Único de Salud (SUS) especializado en gestaciones de medio y alto riesgo. Las interacciones fueron transcritas en su integra y las 18 interacciones en que hay la comunicación de noticias diagnósticas fueron analizadas cuanto a las acciones de interacción que componen esa tarea. El análisis de datos revela que la secuencia de comunicación de noticias (SCN) asume características de una especie de secuencia didáctica que colabora para la construcción del entendimiento de cada situación y para la coconstrución de la propia noticia, tarea que es compartida entre médico y paciente. En la comunicación de malas noticias, en especial, se observa un proceso de agentivización de la revisión médica y de despersonalización de la dolencia. El estudio describe diferentes prácticas lingüístico-interaccionales utilizadas para lidiar con el sufrimiento de pacientes y que pueden subsidiar la formación de profesionales de salud en áreas en que la comunicación de diagnósticos es constante.

Palabras-clave: Asesoramiento genético. Comunicación de noticias. Secuencia didáctica. Agentividad.

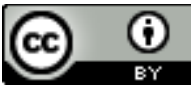

Este texto está licenciado com uma Licença Creative Commons Atribuição 4.0 Internacional.

OSTERMANN, Ana Cristina; FREZZA, Minéia. "Veio o resultado do exame": a comunicação de notícias diagnósticas (e como investigações linguístico-interacionais podem informar as práticas profissionais). Linguagem em (Dis)curso - LemD, Tubarão, SC, v. 17, n. 1, p. 25-50, jan./abr. 2017. 